\title{
Behaviour, welfare, and tibia traits of fast- and slow-growing chickens reared in intensive and free range systems
}

\author{
A. Ghayas ${ }^{\# 1}$, J. Hussain ${ }^{1}$, A. Mahmud ${ }^{1}$, M.H. Jaspal ${ }^{2}$, H.M. Ishaq ${ }^{3}$ \& A. Hussain ${ }^{4}$ \\ ${ }^{1}$ Department of Poultry Production, Faculty of Animal Production and Technology, University of Veterinary and Animal \\ Sciences, Lahore, Pakistan \\ ${ }^{2}$ Department of Meat Science and Technology, Faculty of Animal Production and Technology, University of Veterinary \\ and Animal Sciences, Lahore, Pakistan \\ ${ }^{3}$ Department of Livestock and Poultry Production, Faculty of Veterinary Science, Bahauddin Zakariya University, \\ Multan, Pakistan \\ ${ }^{4}$ Faculty of Veterinary Science, Mirpur University of Science and Technology, Mirpur Azad Jammu; Kashmir, Pakistan
}

(Submitted 27 April 2020; Accepted 10 October 2020; Published 6 January 2021)

\author{
Copyright resides with the authors in terms of the Creative Commons Attribution 4.0 South African License. \\ See: http://creativecommons.org/licenses/by/4.0/za \\ Condition of use: The user may copy, distribute, transmit and adapt the work, but must recognize the authors and the South African \\ Journal of Animal Science.
}

\begin{abstract}
The behaviour, welfare, and tibia characteristics of fast- and slow-growing chickens were evaluated in free-range and intensive production systems. A total of 720 birds of three strains were subjected to these systems after 21 days of rearing under the same intensive environment. Each treatment was replicated six times with 20 birds in each replicate. Data were collected for welfare aspects, including feather condition, footpad, hock joint and tonic immobility, behavioural features, especially feeding or foraging, sitting, walking, scratching, pecking and dust-bathing, and tibia characteristics, including weight, length, width, medullary canal diameter and robusticity index (4 - 8 weeks). Production system had significant effects on all welfare and behaviour aspects of the birds. However, tibia characteristics were not influenced by production system, except for medullary canal diameter. The strains differed significantly in welfare, tibia characteristics and behaviour. For example, the slow-growing strains had better feather condition, footpad d hock joint scores. Significant interactions of strain and production system were noted for all characteristics. It was recommended that Rhode Island Red chickens could be raised under either production system without compromising their welfare or causing adverse effects on leg health.
\end{abstract}

Keywords: behaviour, fast-growing, robusticity index, slow-growing, tibia characteristics, welfare

\#Corresponding author: 2106-phd-1030@uvas.edu.pk

\section{Introduction}

Broiler production is one of the largest food-producing enterprises among poultry businesses. Fastgrowing broilers are bred to produce a lot of meat in a short period. Genetic selection for growth has made modern broilers the fastest-growing farmed species (Hocking, 2014) and feeding strategies have been optimized so much that the broilers can be grown efficiently on low-protein diets (Saleh, 2016). But along with selective breeding for a broiler that produces meat quickly, there is increased incidence of skeletal disorders, which are usually expressed in difficulty in walking, which compromises the welfare of the birds. The main welfare problems in intensively reared broilers include dirty feathers, footpad dermatitis, hock burns, leg problems, and behavioural restrictions (Jacob et al., 2016; Thøfner et al., 2019). There are several ways to measure these traits. Scoring systems to assess the cleanliness of feathers, and footpad and hock joint conditions have been developed in various countries with legislation such as Welfare Quality Protocol in The Netherlands (Welfare Quality $\AA$, 2009). Leg problems are also important concerns for modern broilers and can be assessed from physical activity (Sherlock et al., 2010), and by measuring the morphometric traits of the tibia bone (Van der Pol et al., 2015). Estimates showed that $3 \%$ of all commercial broiler flocks in the United Kingdom and 30\% in the Netherlands (Scientific Committee on Animal Health and Animal Welfare, 2000; Sanotra, 2001) suffered from leg problems.

Animal welfare organizations are creating awareness among the public and poultry producers. In Pakistan, there are opportunities for poultry farmers to expand their businesses by exporting welfare-friendly 
free-range poultry products, especially to the Western world, where consumers are willing to pay a higher price for these products (Mulder \& Zomer, 2017; Gangnat et al., 2018). There is public concern about broiler welfare in all the stages of poultry production. The most important aspect is that commercial broilers are raised in an intensive environment, in which these birds are not able to display their natural behaviour (Bessei, 2018). Unfortunately, poultry producers do not consider these issues in their economics, and tend to focus on the performance of the birds and try to uphold their market share (Hussain et al., 2015; Bessei, 2018). Keeping the consumers' preferences in mind, slow-growing strains were developed several years ago by breeding companies. Initially, breeding of these birds was owned only by French companies such as Sasso Isa Crossbreeding (Chabault et al., 2012). Today, companies such as Grimaud Freres (Hubbard crossing), Aviagen with Rowan Ranger, and Cobb with CobbSasso (Damme et al., 2015) are involved in this business. Currently, slow-growing broilers make up a tiny percentage of the market in the USA, but they have gained a foothold in parts of Europe as well. Slow-growing breeds make up $25-30 \%, 15 \%$ and $7 \%$ of total broiler production in The Netherlands, France, and United Kingdom (Thornton, 2016). Some slowgrowing crossbreds have been developed from indigenous poultry strains, and satisfactory growth performance and meat quality have been reported (Devatkal et al., 2018; 2019). Rural strains are thought to exhibit a slower growth rate (Batool et al., 2018; Hussain et al., 2018) compared with commercial broilers. Rhode Island Red (RIR) chickens may be rewarding as an alternative genotype for small-scale rural poultry farmers who cannot afford environmentally controlled poultry houses. In rural areas, these chickens can be managed easily as free range (Sadef et al., 2015). Poor early growth is a major hurdle in the propagation of rural poultry genotypes on a commercial scale (Hussain et al., 2018). Rhode Island Red chickens are thought to be highly adaptive to harsh climatic conditions, but there is a dearth of scientific information about the welfare, behaviour and tibia characteristics of the breed compared with commercial fast- and slowgrowing strains. Rural enterprises may offer better welfare. Therefore, the present study was planned to compare commercial fast-growing, commercial slow-growing and rural slow-growing broiler strains under intensive and free-range rearing systems.

\section{Materials and Methods}

The current experiment was part of a previous trial (Ghayas et al., 2020), which was approved by the Animal Ethics Committee of the Office of Research Innovation and Commercialization in the University of Veterinary and Animal Sciences (UVAS), Lahore, Pakistan (Letter No. DR/986). This study was conducted at Avian Research and Training Centre (ARTC), Department of Poultry Production, UVAS, Lahore, Pakistan, for eight weeks. The geographical coordinates of ARTC are $31^{\circ} 24^{\prime} 36.90^{\prime \prime} \mathrm{N}$ and '22'31.33" E with an altitude of 210.617 metres.

In total, 720 mixed-sex day-old chicks were procured from commercial sources for three chicken strains (Cobb-500, CobbSasso T88, and Rhode Island Red (240 chicks from each). Cobb-500 as commercial fast-growing (CFG) was procured from HiTech group (Pvt. Ltd), Lahore. Commercial slowgrowing (CSG) CobbSasso chicks were purchased from Salman Poultry, a sub-unit of Sadiq Poultry (Pvt. Ltd) Islamabad , and rural slow-growing (RSG), namely Rhode Island Red, were obtained from Rana Poultry (Pvt. Ltd), Lahore. The day-old chicks were transported to the experimental station in a van in which the temperature of $35^{\circ} \mathrm{C}$ was maintained by a manual heating system connected electronically to the battery. After arrival, the chicks were brooded for one week and allowed to grow in an intensive deep litter floor system for 21 days. A 50-mm layer of rice husk was used as bedding (Runge et al., 2007) and maintained on a need basis, depending on its condition.

At 22 days old, birds were distributed to two production systems according to randomized complete block design, following the factorial experimental plan of $2 \times 3$. Each treatment was replicated six times with 20 birds/replicate. The intensive system provided the birds with floor space of $0.6 \mathrm{~m}^{2}$ per bird. For the freerange system, a pen measuring $3.7 \mathrm{~m} \times 3.1 \mathrm{~m}$ indoor area and the same amount of outdoor access were provided to 20 birds at 3 metres/bird. To ensure that the birds did not mix between replicates, the outdoor area of each replicate was fenced with nylon fishing net (Chaohu Huanyu Fishing Tool Co., Ltd, China) (mesh size $1 \mathrm{~cm}$ ).

Each strain was reared in separate house and pens. For the first 21 days, the chicks were kept in three brooding sheds, each comprising six pens made of wire mesh. During this period, the chicks were provided with a heating source to keep the room temperature at the required level. For the first three days, the temperature of the house was maintained at $34.98{ }^{\circ} \mathrm{C}$ then decreased gradually until to $23.88^{\circ} \mathrm{C}$. Humidity was maintained between $60 \%$ and $65 \%$. Commercial broiler starter diet was offered to the birds for the first week and a grower ration was provided later. Ad libitum feed and water supplies were ensured before the arrival of the chicks to maintain welfare standards. Feed composition, vaccination schedule and outside environment variables were shown in Ghayas et al. (2020). 
The data for overall growth performance and physiological response were published in Ghayas et al. (2020). Weekly feed intake and bodyweight are shown in Figure 1.
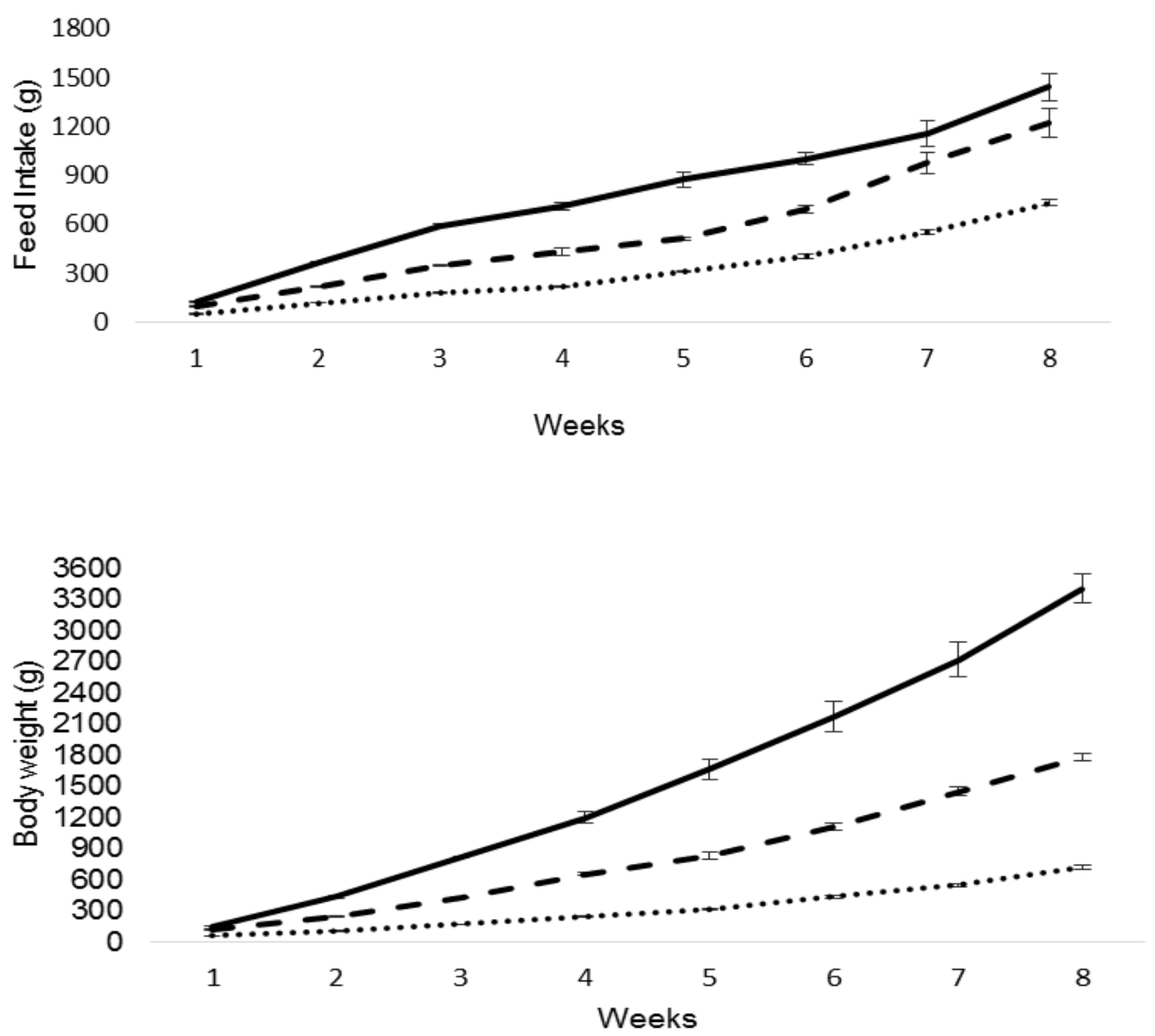

_ Commercial fast-growing _._- Commercial slow-growing ........ Rural slow-growing

Figure 1 Weekly feed intake and bodyweight of commercial fast-growing, commercial slow-growing and rural slow-growing chicken strains

Behavioural observations were recorded weekly in the morning (09h00) and afternoon (17h00), for two periods of three hours, using the focal animal sampling method (Martin \& Bateson, 2007). Frequencies of behaviours were calculated as a percentage of total observed behaviour for feeding, sitting, walking, scratching, pecking and dust-bathing. An ethogram of behavioural parameters is shown in Table 1. Weekly data were converted to average data, which are presented in 'Results'.

Feather conditions were assessed on a three-point scale $(0=$ clean feathers, $1=$ little dirty, $2=$ very dirty feathers). Hock and footpad dermatitis were scored on a five-point scale from no lesions to severe lesions ( 0 = no lesion, 4 = severe lesions) (Welfare Quality, 2009).

At the age of 56 days, two birds from each replicate were slaughtered. The drumstick portion from hip joint to hock joint was separated without damage to the tibia bone (Rehman et al., 2018). The flesh from the bone was separated by boiling in tap water $\left(100^{\circ} \mathrm{C}\right)$ for 20 minutes and removed manually to keep the bone intact. The whole bone was allowed to cool and air-dried for 24 hours. Later, the bones were subjected to measurement of traits such as weight, length, width, and medullary canal diameter. Bone weight was measured on a Japan-made weighing balance scale (BL220H, Shimadzu, Tokyo) with the lowest count of $0.01 \mathrm{~g}$. Morphometric traits of tibia bones were recorded with a Vernier calliper. For medullary canal diameter, each bone was marked in the middle of its length and broken at that point. The thickness of the 
lateral and medial walls was subtracted from the outer bone diameter. Robusticity index (RI) was calculated by dividing the bone length $(\mathrm{mm})$ with the cube root of bone weight $(\mathrm{mg})$ (Kocabağli, 2001).

Table 1 Ethogram of behavioural characteristics of chickens

\begin{tabular}{ll}
\hline Behaviour & Description \\
\hline $\begin{array}{l}\text { Feeding/foraging } \\
\text { Drinking }\end{array}$ & Head above or in the feeder and pecks directed into the feeder or foraging \\
Sitting & Beak on the water in drinker regardless of posture \\
Walking & Lying or sitting with hocks on the ground surface without identifiable motion \\
Scratching & Forward movement at a normal pace or with instant gait \\
Pecking & Backward strokes with legs as if to dig litter or soil \\
Wing flapping & Striking the head or body of a companion bird with beak \\
Dust/litter bathing & Active movement of outstretched wings \\
& On the ground surface, kicking litter/dust on body or wiggling body in litter/dust \\
\hline
\end{tabular}

\section{Results and Discussion}

Differences $(P<0.0001)$ were observed between the two production systems in percentage behaviour (Table 2). The birds under the free-range system showed the highest levels of comfort and natural behaviour, whereas the intensive system was stressful to the birds, of which of a higher $(P<0.0001)$ proportion were observed sitting continuously than in the free-range system. Additionally, pecking was higher $(P<0.0001)$ in intensively reared birds than in free range. Basic need parameters (feeding and drinking) was higher $(P$ $<0.0001)$ in the free-range system than those in the intensive system. Average feeding behaviour under free range was $21.80 \pm 1.09 \%$, whereas under the intensive system it was $16.83 \pm 0.55 \%$. A comparison of the strains in behavioural traits showed differences for behavioural parameters $(P \leq 0.05)$. Comfort behaviour parameters such as walking, wing flapping, scratching and dust-bathing were higher in fast-growing strains. Rhode Island Red showed higher values than CSG, and these strains were both better than CFG. Dustbathing and litter behaviour were higher in slow-growing birds than fast-growing ones $(P \leq 0.05)$. Significant interactions between production system and strain were observed for all the behavioural parameters. Comfort behaviours were higher when slow-growing strains were reared under free-range systems. This valuation was most favourable in outdoor rural chickens, whereas the CSG was lower in behavioural intensity than RIR, but far better than CFG. However, in sitting and undesirable pecking behaviours, CFG showed significantly the highest measures and RIR the lowest. Feeding was the most common behaviour after sitting and was significantly higher in free-range Cobb-500 than other treatments.

Production system exerted a significant impact $(P<.0001)$ on feather condition score, footpad dermatitis and hock join and better scores were recorded in the birds of the free-range system than the birds in the intensive indoor house. Production systems differed significantly $(P<.0001)$ in duration of tonic immobility $(\mathrm{TI})$. Free-range birds had significantly shorter $\mathrm{TI}$ than those under intensive systems. Strains differed $(P<.0001)$ in condition of feathers, footpad and hock joints. Feather condition score was lowest in RSG, followed by CSG, and the lowest or poorest feather condition was observed in CFG. Similarly, footpad and hock joint conditions were better in RSG, followed by those in CSG, and poorest in CFG strains. Significant differences in $\mathrm{TI}$ were observed among strains $(P<.0001)$. The lowest $\mathrm{TI}$ or shortest time was noted in RSG chickens, whereas CSG took time to regain its natural position. Strain and production system interacted significantly for welfare traits. Overall, RSG performed better under the free-range system than all other possible combinations of strain and production system. It had the lowest scores for feather, footpad and hock burns. Additionally, the TI of RSG in the free range and intensive systems was shorter $(P<.0001)$ than the two other strains from either production system. The CSG broilers had generally better indications of welfare $(P<.0001)$ than CFG birds. However, the feather score of free-range CFG was comparable with that of intensively reared CSG. Mean scores of welfare traits with the standard errors are shown in Table 3. 
Table 2 Behavioural performance (\%) of fast- and slow-growing strains under intensive and free-range systems

\begin{tabular}{|c|c|c|c|c|c|c|c|c|}
\hline & Feeding & Drinking & Sitting & Walking & Pecking & Wing flapping & Litter scratching & Dust-bathing \\
\hline \multicolumn{9}{|l|}{ Production system } \\
\hline Intensive & $16.83^{b} \pm 0.55$ & $5.94^{b} \pm 0.29$ & $60.00^{a} \pm 4.18$ & $11.25^{\mathrm{b}} \pm 2.09$ & $2.73^{a} \pm 0.16$ & $1.82^{b} \pm 0.14$ & $1.42^{b} \pm 0.16$ & $2.70^{\mathrm{b}} \pm 0.34$ \\
\hline Free range & $21.80^{\mathrm{a}} \pm 1.09$ & $7.16^{\mathrm{a}} \pm 0.48$ & $44.96^{\mathrm{b}} \pm 4.38$ & $25.60^{a} \pm 3.04$ & $1.56^{\mathrm{b}} \pm 0.10$ & $4.24^{a} \pm 0.41$ & $3.94^{\mathrm{a}} \pm 0.34$ & $5.40^{a} \pm 0.44$ \\
\hline$P$-value & $<.0001$ & 0.0005 & $<.0001$ & $<.0001$ & $<.0001$ & $<.0001$ & $<.0001$ & $<.0001$ \\
\hline \multicolumn{9}{|l|}{ Strain } \\
\hline CFG & $23.07^{\mathrm{a}} \pm 1.33$ & $8.40^{\mathrm{a}} \pm 0.45$ & $76.40^{\mathrm{a}} \pm 2.17$ & $7.20^{\mathrm{C}} \pm 1.64$ & $2.50^{\mathrm{a}} \pm 0.23$ & $2.03^{c} \pm 0.28$ & $1.63^{c} \pm 0.31$ & $2.20^{\mathrm{C}} \pm 0.37$ \\
\hline CSG & $18.73^{b} \pm 0.81$ & $6.08^{b} \pm 0.28$ & $45.35^{\mathrm{b}} \pm 2.95$ & $16.17^{b} \pm 1.81$ & $2.30^{a} \pm 0.24$ & $2.82^{b} \pm 0.23$ & $2.48^{b} \pm 0.29$ & $3.97^{b} \pm 0.40$ \\
\hline $\mathrm{RSG}$ & $16.15^{c} \pm 0.68$ & $5.17^{\mathrm{C}} \pm 0.24$ & $35.68^{c} \pm 2.18$ & $31.91^{a} \pm 3.34$ & $1.63^{b} \pm 0.17$ & $4.25^{\mathrm{a}} \pm 0.69$ & $3.93^{a} \pm 0.58$ & $5.98^{\mathrm{a}} \pm 0.50$ \\
\hline$P$-value & $<.0001$ & $<.0001$ & $<.0001$ & $<.0001$ & $<.0001$ & $<.0001$ & $<.0001$ & $<.0001$ \\
\hline \multicolumn{9}{|l|}{ Interaction } \\
\hline Intensive $\times$ CFG & $19.10^{\mathrm{bc}} \pm 0.62$ & $7.30^{b} \pm 0.17$ & $82.90^{a} \pm 1.70$ & $1.83^{d} \pm 0.19$ & $3.20^{a} \pm 0.18$ & $1.17^{d} \pm 0.16$ & $0.63^{f} \pm 0.14$ & $1.03^{\dagger} \pm 0.14$ \\
\hline Intensive $\times$ CSG & $16.63^{\mathrm{de}} \pm 0.54$ & $5.70^{c d} \pm 0.28$ & $54.67^{\mathrm{C}} \pm 1.43$ & $8.17^{c} \pm 0.25$ & $1.63^{b c} \pm 0.17$ & $2.17^{c} \pm 0.16$ & $1.57^{\mathrm{e}} \pm 0.14$ & $2.70^{\mathrm{e}} \pm 0.15$ \\
\hline Intensive $\times$ RSG & $14.77^{\mathrm{e}} \pm 0.72$ & $4.83^{d} \pm 0.35$ & $42.43^{d} \pm 1.02$ & $21.68^{\mathrm{b}} \pm 2.16$ & $1.80^{\mathrm{b}} \pm 0.07$ & $2.13^{c} \pm 0.18$ & $2.07^{d} \pm 0.13$ & $4.37^{d} \pm 0.06$ \\
\hline Free range $\times \mathrm{CFG}$ & $27.03^{\mathrm{a}} \pm 1.08$ & $9.50^{\mathrm{a}} \pm 0.60$ & $69.90^{\mathrm{b}} \pm 0.98$ & $12.57^{c} \pm 0.54$ & $2.03^{b} \pm 0.20$ & $2.90^{b c} \pm 0.13$ & $2.63^{c} \pm 0.11$ & $3.37^{c} \pm 0.19$ \\
\hline Free range $\times \mathrm{CSG}$ & $20.83^{b} \pm 0.92$ & $6.47^{\mathrm{bc}} \pm 0.45$ & $36.03^{e} \pm 1.19$ & $22.10^{b} \pm 0.50$ & $2.97^{\mathrm{a}} \pm 0.22$ & $3.47^{b} \pm 0.20$ & $3.40^{b} \pm 0.26$ & $5.23^{b} \pm 0.16$ \\
\hline Free Range $\times$ RSG & $17.53^{\mathrm{cd}} \pm 0.85$ & $5.50^{c d} \pm 0.30$ & $28.93^{\dagger} \pm 1.31$ & $42.13^{a} \pm 1.58$ & $1.23^{c} \pm 0.16$ & $6.37^{a} \pm 0.49$ & $5.80^{a} \pm 0.15$ & $7.60^{a} \pm 0.27$ \\
\hline$P$-value & 0.0097 & $<.0001$ & $<.0001$ & 0.0003 & $<.0001$ & $<.0001$ & $<.0001$ & 0.0358 \\
\hline
\end{tabular}

$\overline{a, b, c, d}$ Within a column means with a common superscript were not different with probability $P=0.05$

CFG: commercial fast growing Cobb 500; CSG: commercial slow-growing CobbSasso; RSG: rural slow-growing Red Island Red 
Table 3 Welfare traits of fast- and slow growing strains reared under alternate free-range and intensive systems

\begin{tabular}{|c|c|c|c|c|}
\hline & Feather score & Footpad & Hock burns & $\mathrm{TI}(\mathrm{sec})$ \\
\hline \multicolumn{5}{|l|}{ Production system } \\
\hline Intensive & $1.06^{\mathrm{a}} \pm 0.14$ & $1.84^{\mathrm{a}} \pm 0.26$ & $1.81^{a} \pm 0.28$ & $49.55^{a} \pm 3.82$ \\
\hline Free range & $0.70^{b} \pm 0.13$ & $0.71^{b} \pm 0.16$ & $0.72^{b} \pm 0.16$ & $38.32^{b} \pm 1.66$ \\
\hline$P$-value & $<.0001$ & $<.0001$ & $<.0001$ & $<.0001$ \\
\hline \multicolumn{5}{|l|}{ Strains } \\
\hline CFG & $1.48^{a} \pm 0.07$ & $2.25^{a} \pm 0.22$ & $2.27^{a} \pm 0.22$ & $52.97^{a} \pm 2.76$ \\
\hline CSG & $0.92^{b} \pm 0.12$ & $1.30^{b} \pm 0.28$ & $1.30^{b} \pm 0.28$ & $50.08^{b} \pm 2.90$ \\
\hline RSG & $0.23^{C} \pm 0.04$ & $0.28^{\mathrm{C}} \pm 0.07$ & $0.23^{C} \pm 0.07$ & $28.77^{C} \pm 1.03$ \\
\hline$P$-value & $<.0001$ & $<.0001$ & $<.0001$ & $<.0001$ \\
\hline \multicolumn{5}{|l|}{ Interaction } \\
\hline Intensive $\times$ CFG & $1.63^{\mathrm{a}} \pm 0.06$ & $2.90^{a} \pm 0.18$ & $2.93^{a} \pm 0.18$ & $61.46^{a} \pm 1.56$ \\
\hline Intensive $\times$ CSG & $1.20^{b} \pm 0.15$ & $2.20^{b} \pm 0.09$ & $2.20^{b} \pm 0.09$ & $59.43^{\mathrm{a}} \pm 1.17$ \\
\hline Intensive $\times$ RSG & $0.33^{d} \pm 0.04$ & $0.43^{d} \pm 0.08$ & $0.30^{d} \pm 0.09$ & $27.77^{\mathrm{C}} \pm 1.47$ \\
\hline Free range $\times$ CFG & $1.33^{b} \pm 0.08$ & $1.60^{C} \pm 0.07$ & $1.60^{\mathrm{C}} \pm 0.07$ & $44.47^{b} \pm 1.47$ \\
\hline Free range $\times$ CSG & $0.63^{c} \pm 0.10$ & $0.40^{d} \pm 0.07$ & $0.40^{d} \pm 0.07$ & $40.72^{b} \pm 0.75$ \\
\hline Free Range $\times$ RSG & $0.13^{d} \pm 0.04$ & $0.13^{d} \pm 0.08$ & $0.17^{d} \pm 0.11$ & $29.77^{\mathrm{C}} \pm 1.47$ \\
\hline$P$-value & $<.0001$ & $<.0001$ & $<.0001$ & $<.0001$ \\
\hline
\end{tabular}

${ }_{a, b, c, d}$ Within a column means with a common superscript were not different with probability $P=0.05$

CFG: commercial fast-growing; CSG: commercial slow-growing; RSG: rural slow-growing; TI: tonic immobility

The weight of the tibia was influenced by strain $(P \leq 0.05)$, but not by production system $(P>0.05)$. Tibia weight ( $\mathrm{g}$ ) was highest in CFG, followed by CSG, and the lowest weight was observed in slow-growing RIR chickens (Table 4). Interaction $(P \leq 0.05)$ was observed between treatments. Higher $(P<0.0001)$ tibia weight was observed in intensively raised fast-growing Cobb-500, whereas the lowest was recorded in freerange slow-growing RIR chicken. Free-range and intensively reared CFG differed $(P \leq 0.05)$ in their tibia weights. Statistical analysis showed that production system had a non-significant impact on tibia length $(P$ $>0.05)$. Strains differed significantly in length of the tibia bone $(P<.0001)$. Fast-growing CFG had longer tibia than CSG and RSG. However, in both of the slow-growing strains, the lengths of the tibia were comparable. Interaction between strain and production system was significant $(P<.0001)$. The highest value of tibia length was recorded in intensively reared CFG, followed by intensive CobbSasso and the lowest was observed in free-range RIR. According to the current results, production system did not affect the width of the tibia bone $(P>0.05)$, but strain had a significant impact. Commercial fast-growing Cobb-500 and slow-growing CobbSasso presented a higher value than rural slow-growing chickens. In interactions, Cobb-500 under intensive housing had wider tibia bones than free-range Cobb-500, CobbSasso, and RIR chicken. The reported interaction was also higher than intensively reared RIR, but was non-significantly different $(P>0.05)$ from CobbSasso of the intensive house. Tibia bone medullary diameter was affected by strain $(P<0.0001)$. Commercial strains presented a higher diameter of medullary canal than rural slow-growing RIR. A significant difference was also recorded between the free-range and intensively reared birds $(P=0.001)$. Birds under the free-range system were ranked higher for the diameter of medullary canal than those in the indoor intensive house. Strain and production system interacted significantly for medullary canal diameter. Cobb-500 in the free-range system had significantly greater measures of medullary canal diameter, whereas the intensively reared RIR chickens were lowest. A difference $(P<.0001)$ was observed among the strains for their robusticity index (RI). Rural slow-growing strains were the most robust genotype, followed by CobbSasso, and the poor RI was observed for CFG chickens. However, no effect of production system was observed on overall $\mathrm{RI}$ of the birds $(P=0.9805)$. As far as interactions were concerned, significant differences were observed for RI. RIR chickens under both intensive and free-range system had better indices of tibia robustness, whereas CobbSasso under these systems had intermediate values, and commercial fastgrowing Cobb-500 had poor RI under intensive and free-range systems. 
Table 4 Tibia characteristics of fast- and slow-growing strains under free-range and intensive systems

\begin{tabular}{|c|c|c|c|c|c|}
\hline & Weight, g & Length, mm & Width, mm & $\mathrm{MCD}, \mathrm{mm}$ & $\mathrm{RI}$ \\
\hline \multicolumn{6}{|l|}{ Production system } \\
\hline Intensive & $14.27 \pm 1.68$ & $106.08 \pm 5.73$ & $7.61 \pm 0.51$ & $5.69^{b} \pm 0.31$ & $4.49 \pm 0.07$ \\
\hline Free range & $13.52 \pm 1.48$ & $104.28 \pm 5.29$ & $7.20 \pm 0.39$ & $6.37^{a} \pm 0.27$ & $4.48 \pm 0.07$ \\
\hline$P$-value & 0.0548 & 0.2832 & 0.1571 & 0.001 & 0.9805 \\
\hline \multicolumn{6}{|l|}{ Strain } \\
\hline CFG & $21.45^{a} \pm 0.51$ & $131.06^{a} \pm 1.18$ & $9.02^{a} \pm 0.41$ & $6.88^{a} \pm 0.14$ & $4.72^{a} \pm 0.05$ \\
\hline CSG & $14.53^{b} \pm 0.22$ & $107.76^{b} \pm 1.88$ & $8.08^{b} \pm 0.14$ & $6.67^{a} \pm 0.16$ & $4.42^{b} \pm 0.07$ \\
\hline $\mathrm{RSG}$ & $5.72^{c} \pm 0.29$ & $76.72^{\mathrm{C}} \pm 1.11$ & $5.12^{c} \pm 0.14$ & $4.54^{b} \pm 0.25$ & $4.31^{b} \pm 0.08$ \\
\hline$P$-value & $<.0001$ & $<.0001$ & $<.0001$ & $<.0001$ & 0.0009 \\
\hline \multicolumn{6}{|l|}{ Interaction } \\
\hline Intensive $\times$ CFG & $22.50^{\mathrm{a}} \pm 0.53$ & $133.57^{\mathrm{a}} \pm 1.20$ & $9.71^{a} \pm 0.59$ & $6.43^{b} \pm 0.03$ & $4.73^{a} \pm 0.06$ \\
\hline Intensive $\times$ CSG & $14.68^{\mathrm{C}} \pm 0.36$ & $108.07^{\mathrm{b}} \pm 1.87$ & $8.10^{b} \pm 0.01$ & $6.60^{b} \pm 0.22$ & $4.42^{b c} \pm 0.08$ \\
\hline Intensive $\times$ RSG & $5.63^{d} \pm 0.09$ & $76.61^{\mathrm{c}} \pm 2.08$ & $5.04^{c} \pm 0.25$ & $4.04^{d} \pm 0.32$ & $4.31^{\mathrm{c}} \pm 0.12$ \\
\hline Free range $\times$ CFG & $20.40^{b} \pm 0.64$ & $128.55^{a} \pm 1.48$ & $8.33^{b} \pm 0.47$ & $7.32^{a} \pm 0.08$ & $4.71^{\mathrm{ab}} \pm 0.08$ \\
\hline Free range $\times$ CSG & $14.37^{c} \pm 0.27$ & $107.46^{b} \pm 3.46$ & $8.06^{b} \pm 0.29$ & $6.75^{\mathrm{ab}} \pm 0.26$ & $4.42^{b c} \pm 0.13$ \\
\hline Free Range $\times$ RSG & $5.80^{d} \pm 0.60$ & $76.83^{c} \pm 1.06$ & $5.21^{\mathrm{C}} \pm 0.16$ & $5.03^{c} \pm 0.30$ & $4.32^{c} \pm 0.11$ \\
\hline$P$-value & $<.0001$ & $<.0001$ & $<.0001$ & $<.0001$ & 0.0116 \\
\hline
\end{tabular}

${ }_{a, b, c, d}$ Within a column means with a common superscript were not different with probability $P=0.05$

MCD: medullary canal diameter; RI: robusticity index; CFG: commercial fast growing; CSG: commercial slow growing; RSG: rural slow growing

Dust-bathing and litter behaviour was higher in slow-growing birds than fast-growing ones and the values obtained (2.2 - 5.98\%) were higher compared with earlier literature (10.9\%) (Weeks et al., 2000; Cornetto \& Estevez, 2001; Hall, 2001). Dust-bathing is affected by various factors, of which dust material is important. Free-range birds could access different types of materials during ranging. This might be the reason for the overestimation of dust-bathing behaviour in free range. Better behaviour performance such as more walking, dust-bathing, and wing flapping and more feeding under free range could be attributed to environmental opportunities for the birds such as pasture, insects, soil and other backgrounds (Zhao et al., 2014). In addition, other factors are accountable for behavioural differences such as weather, predators, and light. Significant differences of comfort behaviour among the strains were observed in the current study. Drinking behaviour was higher in the slow-growing chickens raised under the free-range system. In agreement, Elanco Animal Health (2016) pointed out more water might be needed to produce slow-growing chickens because of ambient temperature, increased activity and consumption of energy-rich food resources from the environment (Bruno et al., 2011; Huang et al., 2011).

In earlier studies, growth rate was regarded as one of the major driving force in changing pattern of the chicken's behaviour. Bergmann et al. (2016) reported $26 \%$ poorer mobility in Ross broilers than slowgrowing Sasso chickens. Lower growth rate was associated with better gait scores in broilers (Kristensen et al., 2006; Brickett et al., 2007). The findings in the present study were consistent with there being a negative relationship between growth rate and most of behavioural patterns including mobility (Djukic-Stojcic \& Bessei, 2011). Rural slow-growing chickens had lower bodyweight than fast-growing broilers (Figure 2) and hence might have consequently had better behavioural repertoires than the other strains. The walking ability of the birds had been reported to be associated with body development, especially breast weight, which that may alter the centre of gravity of the birds (Weeks et al., 2000). Possibly, the fast-growing broilers were frustrated because of this imbalance. Strain has been associated with footpad dermatitis and hock burns (Berg, 2004; Mayne, 2005; Luton et al., 2019). The lower activity level in fast-growing Cobb-500 might also be due to footpad conditions which are painful for walking. A higher percentage of activities in slow-growing strains showed that these birds could be easily managed and grown with fewer chances of compromising the skeleton. Additionally, pecking, an undesirable behaviour, was higher $(P<0.0001)$ in intensively reared birds than in free range. Average feeding behaviour for basic need parameters was higher $(P<0.0001)$ in the free- 
range system than in the intensive system. The data suggested that slow-growing strains easily adjust their behaviour to production systems. These adjustments were seen under free-range and intensive housings, which resulted in significant changes in behavioural repertoires.

Lower scoring indicated better welfare traits. Overall, RSG chickens were in better physical condition than commercial CSG and CFG chickens. These findings are in line with those of Luton et al. (2019), who reported poorer conditions of bulky broilers than those of a lighter weight strain. Shorter TI in RSG chickens is in line with findings of Mancinelli et al. (2018), who reported shorter TI duration in Naked neck chickens than commercial fast-growing Ross broilers. Rural chickens are usually reared in free-range systems, have slower growth rate, and undergo harsh conditions during walking on abrasive ground. To protect themselves from harsh climatic conditions they develop better feathers, denser footpad and clean hock joints with less chance of injuries. The differences between the commercial strains and the indigenous chickens could be assigned to various factors, the most critical of which was weight distribution, and the way broilers gain weight during the grow-out period (Alves et al., 2016). The abrupt growth of broilers leads to lower bone development and change of centre of gravity, which might lead to higher TI than slow-growing lightweight birds. Contrary to the current results, Çavuşoglu and Petek (2019) found a longer duration of TI in slowgrowing than fast-growing strains. Production system exerted a significant impact $(P<.0001)$ on feather condition score, footpad dermatitis and hock joint. The birds under the free-range system had better conditions of feathers, footpad and hock joints than those reared under the intensive environment. Riber et al. (2018) concluded that free-range usage improved the conditions of feather, footpad and hock joint. The differences in footpad scores of the birds reared under intensive and free-range systems could be because different types of floor were available to the birds (Cengiz et al., 2013). On the contrary, Stadig et al. (2017) showed that outdoor access did not have any impact on footpad condition. Tonic immobility duration indicates the alertness or fearfulness of the birds (Hata et al., 2018). In the current study, birds with outdoor access presented shorter $\mathrm{TI}$, which that means free-range birds were more alert and responded more quickly to perceived danger. Mutibvu et al. (2017) who observed the shorter duration of $\mathrm{TI}$ in free-range birds than intensively housed birds. Shorter immobility time in free-range birds could be attributed to a higher level of movement. Mahboub et al. (2004) reported a negative correlation between individual movement and TI in laying hens. In contrast, a recent study showed a non-significant effect of production system on $\mathrm{TI}$ (Çavuşoglu \& Petek, 2019).

Tibia weight is an important criterion to evaluate the bone strength (González-Cerón et al., 2015). Similar to the findings of the present study, significantly heavier tibia were reported in fast-growing broilers compared with slow-growing birds (Shim et al., 2012). Selection for growth in contemporary fast-growing broilers resulted in an increase in the relative weight and length of the tibia (Shim et al., 2012). In addition, the genetic basis of bone weight and length in chicken was explained in earlier studies, in which the heritability of weight and length of both leg bones was within the range of 0.44 to 0.69 (de Verdal et al., 2013). Although there was a strong genetic background of growth in broilers, the difference in free-range and intensive CFG might be because of the continuous availability of commercial feed and better growth in the intensive environment. However, the aforementioned findings differ from those from laying hens where it was reported that genotype did not affect the tibia weight (Tůmová et al., 2016). However, the present results confirm those of Tümová et al. (2016) relative to effects of housing system on tibia weight in layers.

The length of the tibia is an important criterion to assess the leg health as it is related directly to the walking ability of broilers. Significant interaction effects on tibia length were recorded in this study. The higher growth rate in CFG chickens could be a reason for longer tibia than RSG chicken. These results suggested that strain can influence leg health directly by slowing bodyweight gain. Hence the selection of appropriate strains in poultry should not be neglected. There is a possibility that genetically defined growth rate had played a role in skeletal growth. Both slow-growing strains had significantly shorter tibia under free range than fast-growing birds under intensive systems. Although free range was available to slow-growing strains, their growth rate was not comparable with Cobb-500. Similar findings were reported in a study in which intensively reared Harco black genotype had higher morphological lengths of tibia than free-range Novogen strains (Sogunle et al., 2012). Contrary to the current findings, Akşit et al. (2017) reported no effect of environmental enrichment on tibia length. Tůmová et al. (2016) reported no effect of strain and housing system on tibia length in laying hens. Cobb-500 had significantly higher tibia width. Similar findings were reported in a study in which male and female strains of turkeys had significantly different widths of the tibia bone (Safiyu et al., 2019). Body size and hormonal differences could induce differences in bone quality (Rath et al., 2000). Although the tibia width of CobbSasso was lower than Cobb-500, it was much higher than RIR.

Robusticity index is an indication of the strength of the bone. Lower values of RI represent more robust bones. Similar to the current findings, a recent study described significantly different Rls between male and female turkeys (Safiyu et al., 2019). Safiyu et al. (2019) showed similar results for production systems in which deep litter and free-range systems did not change the RI of turkeys. According to the literature, heavier 
birds have abnormally developed bones with high porosity and much lower density, which make them less robust than lightweight birds (Bennett, 2008). Reduced robustness in Cobb-500 might be because of production-related processes such as fast growth and high metabolic rate demand so many resources that other internal responses are compromised (Knap, 2005). Overall, RIR had better tibia characteristics than the other two strains. CobbSasso showed slight better performance than Cobb-500, especially when reared in free range. Strain and production system had a significant impact on welfare aspects. Rhode Island Red performed most of the behaviours to a higher level than the other genotypes. Production systems did not have any effect on tibia characteristics except medullary canal diameter.

\section{Conclusions}

When provided with outdoor access the rural slow-growing Rhode Island Red strain had better welfare, robusticity index and behaviours than the commercial strains.

\section{Authors' Contributions}

$\mathrm{JH}$ conceived the experiment and supervised its conduct. AG conducted the research, collected the data and wrote the initial manuscript. HMI conducted statistical analyses and described them in the manuscript. MHJ provided insights for interpretation of results. $\mathrm{AM}$ and $\mathrm{AH}$ revised and formatted the final document.

\section{Conflict of Interest Declaration}

The authors have no conflict of interest relative to this work.

\section{References}

Akşit, M., Yardim, Z.K. \& Yalcin, S., 2017. Environmental enrichment influences on broiler performance and meat quality: Effect of light source and providing perches. European Poult. Sci. 18, 81. DOI: 10.1399/eps.2017.182

Alves, M.C.F., de Lima Almeida Paz, I.C., de Alencar Nääs, I., Garcia, R.G., Caldara, F.R., de Araujo Baldo, G.A., Garcia, E.A. \& de Britto Molino, A., 2016. Locomotion of commercial broilers and indigenous chickens. Rev. Bras. de Zoot. 45(7), 372-379. DOI: 10.1590/S1806-92902016000700003

Batool, T., Farooq, S., Roohi, N., Mahmud, A., Usman, M., Ghayas, A. \& Ahmad, S., 2018. Effect of different dietary lysine regimens on meat quality attributes in varieties of indigenous Aseel chicken. Kafkas Uni. Vet. Fakult. Dergisi. 24, 639-645. DOI: 10.9775/kvfd.2018.19523

Bennett, M.B., 2008. Post-hatching growth and development of the pectoral and pelvic limbs in the black noddy, Anous minutus. Comp. Biochem. Physiol - A Mol. Integ. Physiol. 150(2), 159-168. DOI: 10.1016/j.cbpa.2006.06.011

Berg, C., 2004. Pododermatitis and hock burn in broiler chickens. In: C. A. Weeks \& A. Butterworth (eds). Measuring and auditing broiler welfare. $\mathrm{CABI}$, Wallingford, UK.

Bessei, W., 2018. Impact of animal welfare on worldwide poultry production. World's Poult. Sci. J. 74(2), 211-224. DOI: $10.1017 /$ S0043933918000028

Brickett, K.E., Dahiya, J.P., Classen, H.L. \& Gomis, S., 2007. Influence of dietary nutrient density, feed form, and lighting on growth and meat yield of broiler chickens. Poult. Sci. 86(10), 2172-2181. DOI: 10.1093/ps/86.10.2172

Bruno, L.D.G., Maiorka, A., Macari, M., Furlan, R.L. \& Givisiez, P.E.N., 2011. Water intake behavior of broiler chickens exposed to heat stress and drinking from bell or and nipple drinkers. Braz J Poult Sci. 13(2), 147-152. http://dx.doi.org/10.1590/S1516-635X2011000200009

Çavuşoglu, E. \& Petek, M., 2019. Effects of different floor materials on the welfare and behaviour of slow- and fastgrowing broilers. Arch. Anim. Breed. 62(1), 335. DOI: 10.5194/aab-62-335-2019

Cengiz, Ö., Hess, J.B. \& Bilgili, S.F., 2013. Effect of protein source on the development of footpad dermatitis in broiler chickens reared on different flooring types. Arch. Geflügelk. 77(3),166-70.

Chabault, M., Baéza, E., Gigaud, V., Chartrin, P., Chapuis, H., Boulay, M., Arnould, C., D’Abbadie, F., Berri, C. \& Le Bihan-Duval, E., 2012. Analysis of a slow-growing line reveals wide genetic variability of carcass and meat quality-related traits. BMC Genetics. 13(1), 90. https://doi.org/10.1186/1471-2156-13-90

Cornetto, T. \& Estevez, I., 2001. Behavior of the domestic fowl in the presence of vertical panels. Poult. Sci. 80(10), 1455-1462. DOI: $10.1093 / \mathrm{ps} / 80.10 .1455$

Damme, K., Kepple, C., Hausleitne, M., Bachmeier, J., Hartmann, J., Luton, H. \& Rauch, E., 2015. Test of various premium chicken crosses under animal welfare label conditions. Part I: Fattening and slaughter performance criteria. Europ. Poult. Sci. 79. DOI: 10.1399 / eps.2015.85.

de Verdal, H., Narcy, A., Bastianelli, D., Même, N., Urvoix, S., Collin, A., le Bihan-Duval, E. \& Mignon-Grasteau, S., 2013. Genetic variability of metabolic characteristics in chickens selected for their ability to digest wheat. J. Anim. Sci. 91(1), 2605-2615. DOI: 10.2527/jas.2012-6182

Devatkal, S.K., Naveena, B.M. \& Kotaiah, T., 2019. Quality, composition, and consumer evaluation of meat from slowgrowing broilers relative to commercial broilers. Poult. Sci. 98(11), 6177-6186. https://doi.org/10.3382/ps/pez344

Devatkal, S.K., Vishnuraj, M.R., Kulkarni, V. V. \& Kotaiah, T., 2018. Carcass and meat quality characterization of indigenous and improved variety of chicken genotypes. Poult. Sci. 97, 2947-2956. DOI: 10.3382/ps/pey108

Djukic-Stojcic, M. \& Bessei, W., 2011. The effect of weight load on the legs of broilers behaviour. Biotechnol. Anim. Husb. 27(4), 1667-1671. DOI: 10.2298/bah1104667d 
Gangnat, I.D.M., Mueller, S., Kreuzer, M., Messikommer, R.E., Siegrist, M. \& Visschers, V.H.M., 2018. Swiss consumers' willingness to pay and attitudes regarding dual-purpose poultry and eggs. Poult. Sci. 97(3), 1089-1098. DOI: $10.3382 / p s / p e x 397$

Ghayas, A., Hussain, J., Mahmud, A. \& Jaspal, M.H., 2020. Growth performance, physiological response and economic evaluation of fast- and slow-growing chicken genotypes under two different production environment. S. Afr. J Anim. Sci. 50(3), 378-388. https://dx.doi.org/10.4314/sajas.v50i3.4

González-Cerón, F., Rekaya, R. \& Aggrey, S.E., 2015. Genetic analysis of bone quality traits and growth in a random mating broiler population. Poult. Sci. 94(5), 883-889. DOI: 10.3382/ps/pev056

Hall, A.L., 2001. The effect of stocking density on the welfare and behaviour of broiler chickens reared commercially. Anim. Welfare. 10(1), 23-40.

Hata, M.E., Caetano, S.L., Boleli, I.C. \& Queiroz, S.A., 2018. Genetic and environmental effects on tonic immobility duration of red-winged tinamou applying survival analysis. Rev. Bras. de Cien. Avi. 20(2), 287-296. DOI: 10.1590/1806-9061-2017-0505

Hocking, P.M., 2014. Unexpected consequences of genetic selection in broilers and turkeys: problems and solutions. Brit. Poult. Sci. 55(1), 1-2. DOI: 10.1080/00071668.2014.877692

Huang, K.H., Kemp, C. \& Fisher, C., 2011. Effects of nutrition on water intake and litter moisture in broiler chickens. In 22nd Annual Australian Poultry Science Symposium. p. 26.

Hussain, J., Rabbani, I., Aslam, S. \& Ahmad, H.A., 2015. An overview of poultry industry in Pakistan. World's Poult. Sci. J. 71(4), 689-700. https://doi.org/10.1017/S0043933915002366

Hussain, M., Mahmud, A., Hussain, J., Qaisrani, S.N., Mehmood, S. \& Rehman, A., 2018. Subsequent effect of dietary lysine regimens fed in the starter phase on the growth performance, carcass traits and meat chemical composition of aseel chicken in the grower phase. Rev. Bras. de Cien. Avi., 20(3), 455-462. http://dx.doi.org/10.1590/18069061-2017-0681

Jacob, F.G., Baracho, M.S., Nääs, I.A., Lima, N.S.D., Salgado, D.D. \& Souza, R., 2016. Risk of incidence of hock burn and pododermatitis in broilers reared under commercial conditions. Rev. Bras. de Cien. Avi. 18(3), 357-362. http://dx.doi.org/10.1590/1806-9061-2015-0183

Knap, P.W., 2005. Breeding robust pigs. Anim. Prod. Sci. 45(8), 763-773. https://doi.org/10.1071/EA05041

Kocabağli, N., 2001. The effect of dietary phytase supplementation at different levels on tibial bone characteristics and strength in broilers. Turkish J. Vet. Anim. Sci. 25(5), 797-802.

Kristensen, H.H., Perry, G.C., Prescott, N.B., Ladewig, J., Ersbøll, A.K. \& Wathes, C.M., 2006. Leg health and performance of broiler chickens reared in different light environments. Brit. Poult. Sci. 47(3), 257-263. doi: $10.1080 / 00071660600753557$

Luton, H., Keppler, C., Erhard, M., van Tuijl, O., Bachmeier, J., Damme, K., Reese, S. \& Rauch, E., 2019. Animal-based welfare indicators of 4 slow-growing broiler genotypes for the approval in an animal welfare label program. Poult. Sci. 98(6), 2326-2337. DOI: 10.3382/ps/pez023

Mahboub, H.D.H., J Müller, J. \& von Borell, E., 2004. Outdoor use, tonic immobility, heterophil/lymphocyte ratio and feather condition in free-range laying hens of different genotype. Br. Poult. Sci. 45(6), 738-744. DOI: 10.1080/00071660400014267.

Mancinelli, A.C., Mugnai, C., Castellini, C., Mattioli, S., Moscati, L., Piottoli, L., Guarino Amato, M., Doretti, M., Dal Bosco, A., Cordovani, E., Abbate, Y. \& Ranucci, D., 2018. Effect of transport length and genotype on tonic immobility, blood parameters and carcass contamination of free-range reared chickens. Italian J. Anim. Sci. 17(3), 557-564. DOI: $10.1080 / 1828051 X .2018 .1423583$

Martin, P. \& Bateson, P., 2007. Measuring behaviour: an introductory guide, third edition, Cambridge University Press. Cambridge, New York.

Mayne, R.K., 2005. A review of the aetiology and possible causative factors of foot pad dermatitis in growing turkeys and broilers. World's Poult. Sci. J. 61(2), 256-267. DOI: 10.1079/wps200458

Mulder, M. \& Zomer, S., 2017. Dutch consumers' willingness to pay for broiler welfare. J. Appl. Anim. Welfare Sci. 20(2), 137-154. DOI: 10.1080/10888705.2017.1281134

Mutibvu, T., Chimonyo, M. \& Halimani, T.E., 2017. Physiological responses of slow-growing chickens under diurnally cycling temperature in a hot environment. Rev. Bras. de Cien. Avi. 19(4), 567-576. http://dx.doi.org/10.1590/18069061-2017-0485

Rath, N.C., Huff, G.R., Huff, W.E. \& Balog, J.M., 2000. Factors regulating bone maturity and strength in poultry. Poult. Sci. 79(7), 1024-1032. DOI: 10.1093/ps/79.7.1024

Rehman, H.F., Zaneb, H., Masood, S., Yousaf, M.S., Ashraf, S., Khan, I., Shah, M., Khilji, M.S. \& Rehman, H., 2018. Effect of moringa oleifera leaf powder supplementation on pectoral muscle quality and morphometric characteristics of tibia bone in broiler chickens. Rev. Bras. de Cien. Avi. 20(4), 817-824. DOI:10.1590/1806-90612017-0609

Riber, A.B., Van De Weerd, H.A., De Jong, I.C. \& Steenfeldt, S., 2018. Review of environmental enrichment for broiler chickens. Poult. Sci. 97(2), 378-296.

Sadef, S., Khan, M.S. \& Rehman, M.S., 2015. Indigenous chicken production in Punjab: A detailed survey through participatory rural appraisals. J. Anim. Plant. Sci. 25, 1273-1282.

Safiyu, K., Sogunle, O., Egbeyale, L., Shittu, T., Odutayo, O., Mustapha, J. \& Elangovan, A. V., 2019. Evaluation of growth traits and tibiae health in sexed indigenous turkeys with different feather colours under deep litter and outdoor run houses. Bullet. Uni. Agri. Sci. Vet. Med. Cluj-Napoca. Vet. Med. 76, 1. DOI: 10.15835/buasvmcn$\mathrm{vm}: 2018.0049$ 
Saleh, A.A., 2016. Effect of low-protein in iso-energetic diets on performance, carcass characteristics, digestibilities and plasma lipids of broiler chickens. Egypt Poult. Sci. J. 36(1), 251-62.

Sanotra, G.S., Lund, J.D., Ersbøll, A.K., Petersen, J.S. \& Vestergaard, K.S., 2001. Monitoring leg problems in broilers: a survey of commercial broiler production in Denmark. World's Poult. Sci. J. 57(1), 55-69. DOI: 10.1079/wps20010006

Scientific Committee on Animal Health and Animal Welfare., 2000. The Welfare of chickens kept for meat production (broilers). European Commission, Health and Consumer Protection Directorate-General. Report No. SANCO.B.3/AH/R15/2000.

Sherlock, L., Demmers, T.G.M., Goodship, A.E., Mccarthy, I.D. \& Wathes, C.M., 2010. The relationship between physical activity and leg health in the broiler chicken. Brit. Poult. Sci. 51(1), 22-30. DOI: 10.1080/00071660903460637

Shim, M.Y., Karnuah, A.B., Anthony, N.B., Pesti, G.M. \& Aggrey, S.E., 2012. Genetics, the effects of broiler chicken growth rate on valgus, varus, and tibial dyschondroplasia. Poult. Sci. 91(1), 62-65. DOI:10.3382/ps.2011-01599

Sogunle, O.M., Olaniyi, O.A., Egbeyale, L.T., Akinola, O.S., Shittu, T.A., Abiola, S.S., Ladokun, A.O. \& Sobayo, R.A., 2012. Free range and deep litter poultry production systems: effect on performance, carcass yield and meat composition of cockerel chickens. Trop. Anim. Health. Prod. 45(1), 281-288. DOI:10.1007/s11250-012-0213-2

Stadig, L.M., Rodenburg, T.B., Ampe, B., Reubens, B. \& Tuyttens, F.A.M., 2017. Effect of free-range access, shelter type and weather conditions on free-range use and welfare of slow-growing broiler chickens. Appl. Anim. Behav. Sci. 192, 15-23. DOI: 10.1016/j.applanim.2016.11.008

Thornton, G., 2016. The expanding market for slow-growing broilers. https://www.wattagnet.com/articles/28132-theexpanding-market-for-slow-growing-broilers? $\mathrm{v}=$ preview

Thøfner, I.C.N., Poulsen, L.L., Bisgaard, M., Christensen, H., Olsen, R.H. \& Christensen, J.P., 2019. Correlation between footpad lesions and systemic bacterial infections in broiler breeders. Vet. Res. 50(1), 38. DOI: 10.1186/s13567019-0657-8

Tůmová, E., Vlčková, J., Charvátová, V., Drábek, O., Tejnecký, V., Ketta, M. \& Chodová, D., 2016. Interactions of genotype, housing and dietary calcium in layer performance, eggshell quality and tibia characteristics. S. Afri. J. Anim. Sci. 46(3), 285-293. DOI: 10.4314/sajas. v46i3.8

Van der Pol, C.W., Molenaar, R., Buitink, C.J., Van Roovert-Reijink, I.A.M., Maatjens, C.M., Van Den Brand, H. \& Kemp, B., 2015. Lighting schedule and dimming period in early life: Consequences for broiler chicken leg bone development. Poult. Sci. 94(12), 2980-2988. DOI: 10.3382/ps/pev276

Weeks, C.A., Danbury, T.D., Davies, H.C., Hunt, P. \& Kestin, S.C., 2000. The behaviour of broiler chickens and its modification by lameness. Appl. Anim. Behav. Sci. 67(1), 111-125. DOI: 10.1016/S0168-1591(99)00102-1

Welfare Quality $\AA$, 2009. Welfare Quality Assessment Protocol for Poultry (broilers, laying hens). https://www.researchgate.net/publication/263444443_Welfare_QualityR_Assessment_Protocol_for_Poultry_Broile rs_Laying_Hens

Zhao, Z.G., Li, J.H., Li, X. \& Bao, J., 2014. Effects of housing systems on behaviour, performance and welfare of fastgrowing broilers. Asian-Austral. J. Anim. Sci. 27(1), 140-146. http://dx.doi.org/10.5713/ajas.2013.13167 